\title{
基于西门子 S7-200 PLC 的火电厂漏风控制系统设计
}

\section{The Design of Air Leakage Control System for Power Plant Based on Siemens S7-200 PLC 刘凯伟}

\author{
Kaiwei Liu
}

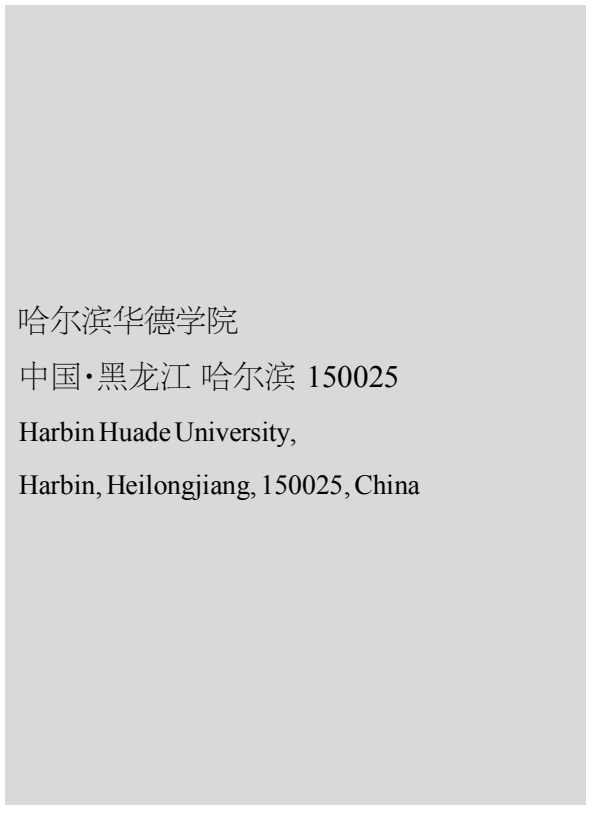

【摘要】论文设计了一种火电厂回转式空气预热器漏风控制系统, 系统由上位机、 S7-200PLC、探测器、执行机构等组成。以 PLC 为控制核心, 通过间隙传感器检测扇形板的 底面与径向密封片之间的间隙值, 采用温度传感器检测烟气和空气入口、出口的温度, 采用 上位机显示当前的状态并进行参数设定等相关控制。该系统运行可靠、故障率低, 实现了控 制空预器漏风率的目的。

【Abstract \This paper designs a air leakage control system of rotary air preheater in thermal power plant. The system consists of upper computer, S7-200 PLC, detector and actuator. With PLC as the control core, the gap between the bottom of the fan plate and the radial sealing plate is detected by the gap sensor, the temperature sensor is used to detect the temperature of the flue gas and air inlet and outlet, and the upper computer is used to display the current state and set parameters. The system runs reliably and has low failure rate, which realizes the purpose of controlling air leakage rate of air preheater.

【关键词】漏风控制; 可编程控制器; 上位机

【Keywords \air leakage control; programmable controller; host computer

【DOI】10.36012/etr.v1i2.256

\section{1 引言}

按照空气预热器的工艺要求, 应尽可能地减小热端径向 密封间隙, 以达到减小漏风的目的。本系统通过温度传感器 采集空气进口、空气出口、烟气进口、烟气出口的温度, 采用间 隙传感器检测出扇形板对转子法兰面之间的间隙值, 通过 PLC 处理温度和间隙信号、发出指令给提升机构控制扇形板 上升或下降,通过上位机监控系统, 可实现自动运行。另外, 还 设有现场手动调节按钮, 可实现现场调节执行机构。本系统能 实现控制空预器漏风率降至 7\%以下，使空气预热器漏风率 大幅下降, 实现节能降耗的目的 ${ }^{[1]}$ 。

\section{2 控制系统设计}

本系统包含 14 个 $\mathrm{I} / \mathrm{O}$ 点。其中, 输入部分包括手自动 选择、手动输入、自动输入、外部限位、电机保护等; 输出部 分包括执行机构、状态显示等。该系统不仅满足了系统设 计要求, 同时又留有足够的余量, 为后期系统升级改造提 供空间。

\section{3 信号采集系统设计}

本系统采用 2 个模拟量输入模块 EM231, 采集间隙传感 器信号、空气进口温度信号、空气出口温度信号、烟气进口温 度信号、烟气出口温度信号。以上信号输入的类型均为 4$20 \mathrm{~mA}$ 信号。采集系统电路原理,如图 1 所示。

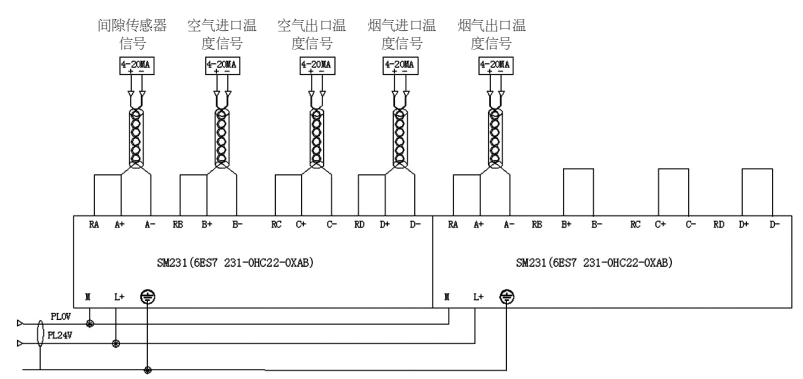

图 1 模拟量扩展模块的接线图

\section{4 系统主电路设计}

主电路为执行机构电路, 通过 PLC 控制继电器输出, 通 过继电器辅助触点控制接触器线圈, 可实现控制执行机构电 
机, 从而调整扇形板间隙。系统主电路图如图 2 所示。

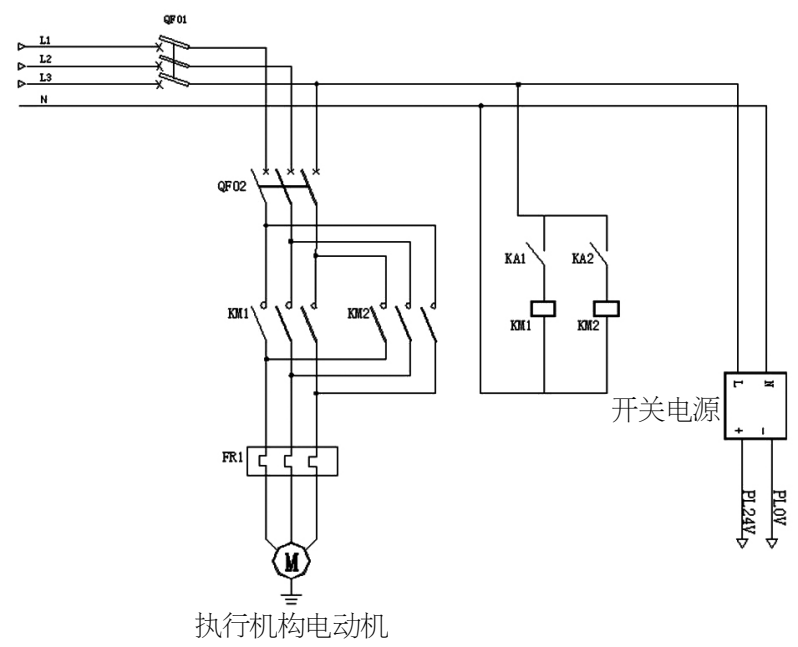

图 2 系统主电路图

\section{5 控制程序设计}

\section{$5.1 \mathrm{I} / \mathrm{O}$ 分配表}

根据工艺要求, 进行 $I / O$ 分配设计。在程序设计时, 可方 便查询、排查故障。本系统对于 $\mathrm{I} / \mathrm{O}$ 分配留有足够余量, 可满 足后期的扩展需要。

\section{2 程序流程}

本系统程序流程设计分为 3 部分设计, 分别为模拟量信 号处理及当前值显示; 手动控制执行机构上行和下行; 自动检 测并比较控制间隙, 输出执行机构动作。

对于温度信号和间隙探测信号, 进行模拟量信号转换, 输 出监控数据, 通过上位机监控, 显示当前实时数值。当主电路 过热过载时, 系统停止运行。当选择手动控制时, 执行机构通 过外部按钮控制, 并由限位开关进行保护; 当选择自动控制 时, 进行间隙值和设定的上限值和下限值比较, 控制相应输出 动作 ${ }^{[2]}$ 。

\subsection{PLC 程序设计}

对模拟量信号进行处理, 首先对模拟量的范围进行限制, 如果超出范围，将限制值赋予该值。将 0-25600 对应 0-100 的现场实时值, 并输出。VD36 为间陌实时值, VD66 为空气进 口温度实时值, VD96 为空气出口温度实时值, VD126 为烟气 进口温度实时值, VD156 为烟气出口温度实时值。

当系统选择手动控制时, 按下外部上行按钮, 执行机构上 行, 当遇到上限位开关, 执行机构停止运行; 按下外部下行按 钮, 执行机构下行, 当遇到下限位开关, 执行机构停止运行。

当外部选择开关选择自动控制时, 系统自动启动后, 将 进行间隙反馈值和给定上限值或下限值的比较, 如果间隙
反馈值 VD36 大于上限值 VD160, 将产生相应的上行动作; 如 果间隙反馈值 VD36 小于下限值 VD164, 将产生相应的下行 动作。

\section{6 上位机系统设计}

按照本系统要求, 在上位机界面对漏风控制系统的进风 口空气温度、出风口空气温度、进风口烟气温度、出风口烟气 温度、间隙实时值进行信号监控; 对手/自动选择状态、限位开 关状态、报警状态等进行显示、对当前扇形板位置进行监控， 并且显示当前执行机构电机状态。系统采用联机控制, 对 S7200 可编程控制器采用 PPI 通讯, 建立数据库变量, 并设置变 量属性。对画面采用动画连接,达到人机界面设计的要求。

画面设计主要包括以下几部分：首先是按钮的设计; 其 次是图形的设计,可以进行图形绘制,也可以进行图形添加; 再次是变量的设置, 每个图形或按钮, 以及状态指示等, 都需 要通过变量进行连接; 然后是动画的设计, 通过动画设计可 以完成动态的流程, 动画设计比较丰富, 通过实际项目的设 计进行选择,比如颜色的变化,图形的移动等; 最后是状态监 控的设计 ${ }^{[3]}$

完成了上述设计后首先将程序下载到 PLC，进行系统运 行。然后按照组态王的设备通信设置,进行组态王和 PLC 之间 的通信连接, 可编程控制器内的数据将通过上位机进行实时 显示。将组态王软件设置为运行模式, 按照系统设计的工艺要 求, 进行组态王软件的调试,调试步骤按照手动调试和自动调 试 2 种方法进行。

\section{7 结语}

本文设计了一种回转式空气预热器漏风控制系统, 通过 对扇形板底面和径向密封片进行间隙测量，来达到控制漏风 率的目的。按照工艺的详细分析, 采用可编程控制器+上位机 的设计方案, 选用可编程控制器为 S7-200 CPU226, 模拟量扩 展模块为 EM231, 选用温度传感器为 PT100。本系统可靠性 高, 故障率低, 可扩展性强, 能实现手/自动控制, 可自动无人管 理控制, 能有效降低漏风率, 对于提高火电厂能源利用效率有 重要意义。

\section{参考文献}

[1]陈忠华.可编程控制器与工业自动化系统[M].北京:机械工业出 版社,2009.

[2]王永华.现代电气控制及 PLC 应用技术 [M].北京:航空航天大 学出版社,2013.

[3]刘树青.西门子 PLC 开发人门与典型实例[M].北京: 人民邮电 出版社,2015. 